\title{
Spontaneous Sublingual Haematoma in a 90-year Old Patient: A Complication of Direct Oral Anticoagulants
}

\author{
Johannes Daniël Cnossen*, Jeannette Fenna Schoonderbeek, Maaike Muller \\ Ikazia Hospital Rotterdam, The Netherlands
}

\begin{abstract}
Sublingual haematoma is a rare complication of anticoagulants and can be life-threatening. As the number of prescribed anticoagulants is increasing, the incidence of complications of these drugs will continue to increase. A report of a sublingual haematoma in an elderly patient with chronic atrial fibrillation treated with edoxban (Lixiana (), Daiichi Sankyo Europe GmbH, München, Germany) is reported. A 90-year male presented at the emergency department with an obstructed upper airway due to a sublingual haematoma. The patient received tranexamic acid, prothrombin complex, and fresh frozen plasma. After fiberoptic nasal intubation, the patient was monitored in the intensive care unit. After four days, the patient was extubated, and after six days, the swelling resolved completely. Complications of anticoagulants are rare but can be life-threatening. Recognition of an endangered airway and reversing the effects of the anticoagulant are essential. Surgical evacuation of the haematoma could be considered but is not necessary.
\end{abstract}

Keywords: sublingual haematoma, spontaneous haematoma, direct oral anticoagulants

Received: 6 June 2019 / Accepted: 30 January 2020

\section{INTRODUCTION}

Anticoagulant drugs are globally one of the most prescribed drugs and the number of patients who use them is increasing $[1,2]$. Indications for anticoagulant therapy are pulmonary embolism, deep venous thrombosis, vascular thromboembolism, peripheral arterial disease, atrial fibrillation, mechanical valve replacement, and ischemic stroke. One of the most common side effects of anticoagulant therapy is a spontaneous haematoma or spontaneous bleeding. Usually, these occur in the gastrointestinal tract, intracranial, retroperitoneal, or in the retropharyngeal space [2]. A rare complication of anticoagulants, due to an increased coagulopathy, is a spontaneous sublingual haematoma. This is also known as "pseudo-Ludwig's phenomenon" [3]. There are only a few case reports describing this phenomenon, mostly due to warfarin or acenocoumarol [4-9]. Vitamin K antagonists (VKAs) reduce the synthesis of functional vitamin K-dependent coagulation enzymes; thus, the effects of warfarin or acenocoumarol can be reversed by prescribing vitamin $\mathrm{K}$.

The case of a 90-year old man with a spontaneous sublingual haematoma who was taking Lixiana $\odot$ is presented. Edoxaban, the active ingredient of Lixiana $\odot$, is one of the four direct oral anticoagulants (DOAC) available. DOAC are directed against thrombin IIa (dabigatran) or factor Xa (rivaroxaban, apixaban, and edoxaban) [10-11].

\section{CASE REPORT}

A 90-year old male patient was brought to the emergency department (Ikazia Hospital, Rotterdam, the Netherlands) with an obstructed upper airway due to a spontaneous sublingual swelling. The patient's medical history revealed chronic atrial fibrillation treated with edoxban (Lixiana @), Daiichi Sankyo Europe GmbH, München, Germany).

There was no history of trauma before the progressive obstruction of the upper airway. The patient was able to speak on arrival at the hospital. During the initial assessment, the patient developed slurred speech and became anxious due to the progressive swelling of the sublingual area. On physical examination, the oral cavity showed a purple mass on the floor of the mouth. The patient had a normal arterial blood oxygen saturation level of $98 \%$ when a nasal cannula administered three litres oxygen. 
His blood pressure was $220 / 100 \mathrm{mmHg}$ with an irregular pulse rate of $110 \mathrm{bpm}$. No cardiogenic muffles were heard on auscultation.

Laboratory results showed a haemoglobin value of $15.5 \mathrm{~g} / \mathrm{dl}(9.4 \mathrm{mmol} / \mathrm{L})$, a thrombocyte count of 204 (150-400 $\left.\times 10^{9}\right)$, a normal internationalized ratio of 1.2 (2.5-4.0), prothrombin time of 13 (9-11) seconds, and partial prothrombin time of 28 seconds.

The patient was prescribed an $1 \mathrm{ml}$ epinephrine spray $(1 \mathrm{mg} / \mathrm{ml}$, Centrafarm B.V., Etten-Leur, The Netherlands) and $4 \mathrm{mg}$ intravenous dexamethasone (Centrafarm B.V., Etten-Leur, The Netherlands) to reverse the swelling. The effects of the direct oral anti- coagulant were reversed with $1000 \mathrm{mg}$ tranexamic acid (Pfizer B.V., Capelle aan de Ijssel, The Netherlands), 1000IE prothrombin complex concentrate (Cofact $\odot$ ) (CSL Behring, Breda, The Netherlands), and two units of fresh frozen plasma (Octapharma $\mathrm{GmbH}$, Wenen, Austria). Tranexamic acid, prothrombin complex, and fresh frozen plasma were all administered intravenous.

The patient was brought to surgery to secure the airway. This was achieved with emergency fiberoptic nasal intubation. A CT-scan was obtained after intubation, which is shown in figures 1-4.

The oral anticoagulant was discontinued when patient arrived at the emergency department. After in-

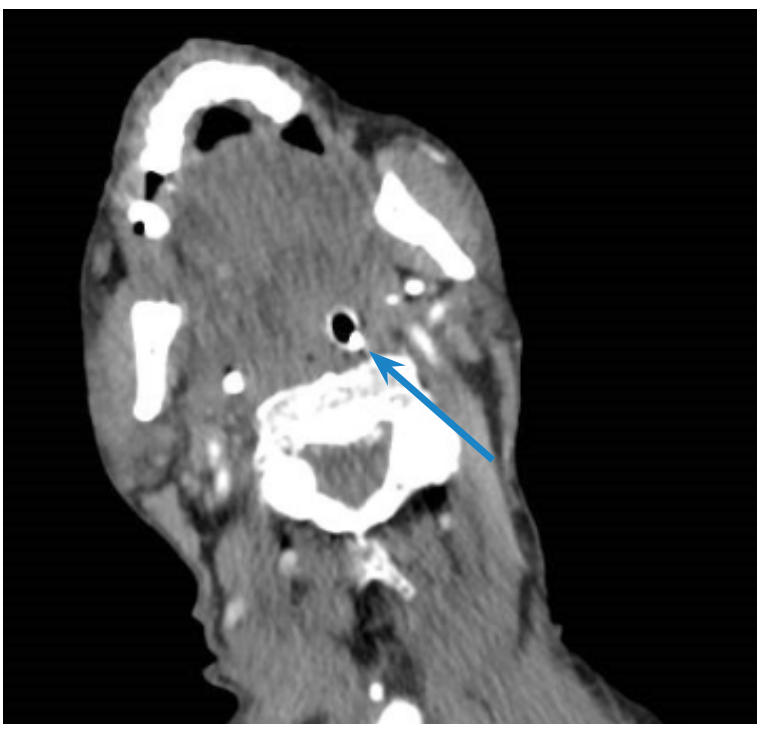

Fig. 1. Axial image shows a compromised upper airway, and the intubation canula (marked with arrow).

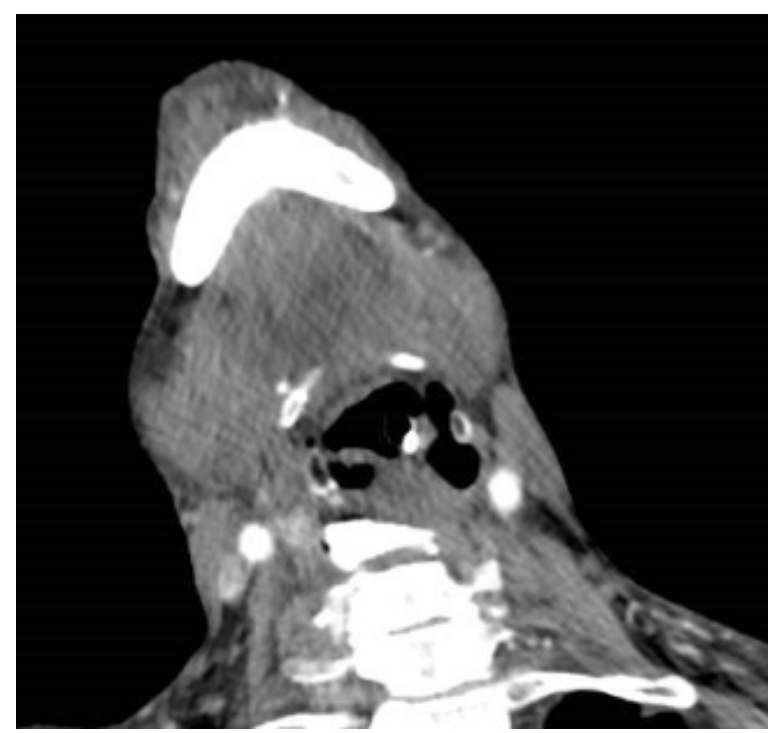

Fig. 2. Axial plane. Extension of swelling in the submandibular region, mostly on the right side.

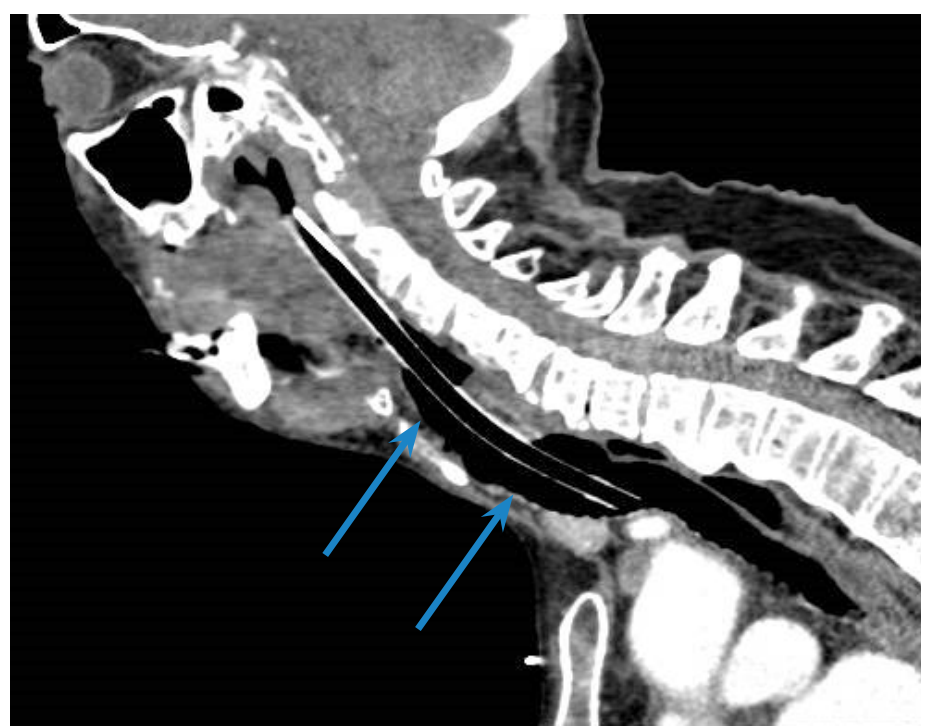

Fig. 3. Sagittal plane. Caudally/bellow from the os hyoideum the CT shows a normal airway (marked with arrows).

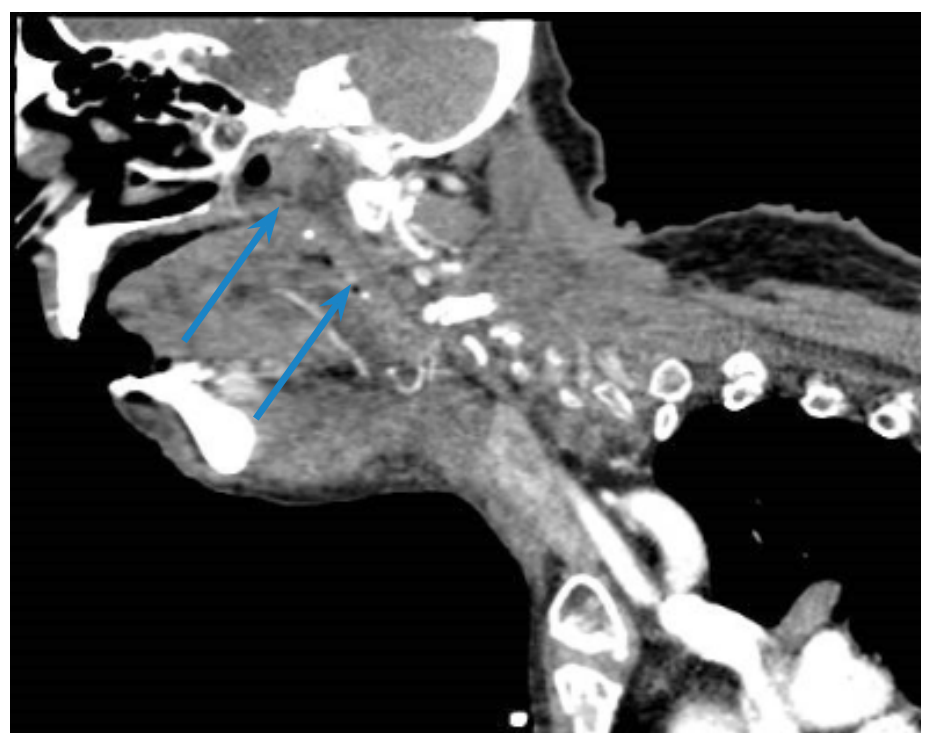

Fig. 4. From the base of the tongue, the vascular structures were prominent, but there was no arterial blush in the tongue (marked with arrows). 
tubation, the patient was brought to the intensive care unit for observation, were he remained intubated for four days.

In the following days, it was not necessary to give additional fresh frozen plasma or tranexamic acid. An ENT-specialist conducted a fiberoptic endoscopy on the fourth day after admission, which showed an almost wholly resolved swelling. The patient was extubated after consulting the ENT-specialist. Post-estuation, the patient was able to speak. An arterial blood oxygen saturation level $>90 \%$ was maintained with two litres of supplemental oxygen.

The swelling had resolved entirely on the sixth day of admission (Figures 5).

\section{DISCUSSION}

This is a case report of sublingual haematoma after the use of direct oral anticoagulants. Spontaneous sublingual haematomas are rare but can have severe consequences as shown by the current case report.

The patient used Lixiana $\odot$. This is the most recently approved DOAC in the Netherlands. Since its distribution in 2011, the number of patients using edoxaban has increased [2]. In recent years, direct oral anticoagulants have been accepted as an alternative for VKAs. Recent studies have shown that DOAC significantly reduces the incidence of haemorrhagic stroke and intracranial haemorrhage compared to VKAs $[12,13]$. DOAC are associated with an increased incidence of gastrointestinal haematomas, but the incidence of major gastrointestinal haemorrhage is lower compared to VKA [12-14].

One of the disadvantages of DOAC is the lack of a widely available specific antidote [15]. Recently two

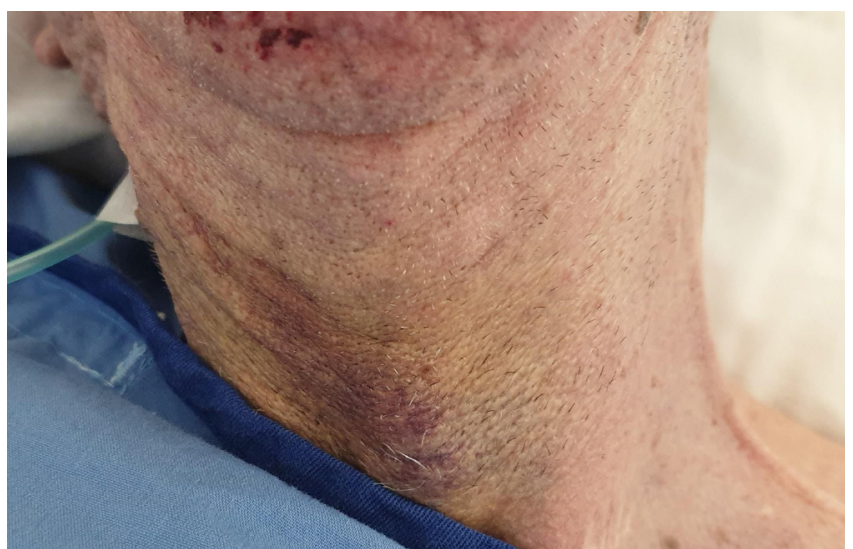

Fig. 5. Migrated haematoma on the lower neck, after 6 days. Published with permission of the patient. new antidotes for direct oral anticoagulants have been developed. The first is idarucizumab which is a specific antidote for dabigatran. Idarucizumab is a monoclonal antibody with a $>350$-fold greater affinity for thrombin than dabigatran [16]. More recently, ciraparantag, which is a synthetic water-soluble molecule, has been developed. Ciraparantag is a universal antidote to DOAC that binds heparin, direct factor Xa inhibitors, and thrombin inhibitors $[10,11,17]$.

In our opinion, it is best to start general treatment of a spontaneous haemorrhage on arrival at an emergency department. As there is not yet a widely accepted antidote for the treatment of DOAC, initial treatment should consist of reversal of the coagulopathy with tranexamic acid, prothrombin complex, and fresh frozen plasma.

A spontaneous sublingual haematoma is rare but can have enormous consequences which require both adequate and quick treatment. A possible endangered airway should be secured. Endotracheal intubation is preferred, but with a sizeable sublingual swelling, this may be complicated. The first choice of treatment when endotracheal intubation fails is nasal endoscopic endotracheal intubation. In an unsuccessful procedure, a tracheostomy or a cricothyrotomy could be performed to secure the airway.

A review from Karmacharya et al. (2015) shows that the mean resolution of haematoma was 7.69 days ( \pm 5.44 days). They found no difference in time to resolution of the haematoma in patients who received only medical treatment (vitamin K, FFP, or prothrombin complex concentrate) compared to patients who received medical treatment and treatment for compromised upper airway (cricothyrotomy, tracheotomy, or endotracheal intubation) [18]. In the same review, it was reported that in only one case of sublingual haematoma was surgical incision necessary. In our opinion, surgical intervention should be withheld, as in most case reports the haematoma has been shown to resolve in a few days.

\section{- CONCLUSION}

The topic is of high interest, given the fact that more and more patients receive $\mathrm{DOAC}$ as an alternative to traditional anticoagulant treatment. Also, a sublingual haematoma can be a life-threatening condition which needs to be treated promptly and adequately. Initial treatment should consist of early recognition of a criti- 
114 The Journal of Critical Care Medicine 2020;6(2)

cal upper airway and reversal of the effects of the anticoagulant drug.

It is to be noted that for the relatively new direct oral anticoagulants, an antidote is not always available. Surgical incision of the swelling is possible, but not indicated as the swelling usually resolves in a few days.

\section{- CONFLICT OF INTEREST}

All authors declare no conflict of interest. No funding or financial support was received.

\section{口EFERENCES}

1. Kantor ED, Rehm CD, Haas JS, Chan AT, Giovannucci EL. Trends in Prescription Drug Use Among Adults in the United States From 1999-2012. JAMA. 2015;314(17):1818-31.

2. LAREB DD. Update overview 2019 of reports on direct oral anticoagulants (DOACs) and the antidote idarucizumab.: LAREB; 2019 https://databankws.lareb.nl/Downloads/Signals_2019_ DOACs_update_overview\%202019.pdf.

3. Lepore ML. Upper airway obstruction induced by warfarin sodium. Arch Otolaryngol. 1976;102(8):505-6.

4. Gonzalez-Garcia R, Schoendorff G, Munoz-Guerra MF, Rodriguez-Campo FJ, Naval-Gias L, Sastre-Perez J. Upper airway obstruction by sublingual haematoma : a complication of anticoagulation therapy with acenocoumarol. Am J Otolaryngol. 2006;27(2):129-32.

5. Cashman E, Shandilya M, Amin M, Hughes J, Walsh M. Warfarininduced sublingual haematoma mimicking Ludwig angina: Conservative management of a potentially life-threatening condition. Ear Nose Throat J. 2011;90(2):E1.

6. Frohna WJ, Lowery RC, Jr., Pita F. Lingual and sublingual haematoma causing upper airway obstruction. J Emerg Med. 2012;43(6):1075-6.

7. Puri A, Nusrath MA, Harinathan D, Lyall J. Massive sublingual haematoma secondary to anticoagulant therapy complicated by a traumatic denture: a case report. J Med Case Rep. 2012;6:105.
Available online at: www.jccm.ro

8. Lovallo E, Patterson S, Erickson M, Chin C, Blanc P, Durrani TS. When Is "Pseudo-Ludwig's Angina" Associated With Coagulopathy Also a "Pseudo" Hemorrhage? J Investig Med High Impact Case Rep. 2013;1(2):2324709613492503.

9. Pathak R, Supplee S, Aryal MR, Karmacharya P. Warfarin induced sublingual haematoma : a Ludwig angina mimic. Am J Otolaryngol. 2015;36(1):84-6.

10. Almegren M. Reversal of direct oral anticoagulants. Vasc Health Risk Manag. 2017;13:287-92.

11. Palaiodimos L, Miles J, Kokkinidis DG, Barkolias C, Jonnalagadda AK, Papaconstantinou D, et al. Reversal of Novel Anticoagulants in Emergent Surgery and Trauma: A Comprehensive Review and Proposed Management Algorithm. Curr Pharm Des. 2018;24(38):4540-53.

12. Hylek EM, Held C, Alexander JH, Lopes RD, De Caterina R, Wojdyla DM, et al. Major bleeding in patients with atrial fibrillation receiving apixaban or warfarin: The ARISTOTLE Trial (Apixaban for Reduction in Stroke and Other Thromboembolic Events in Atrial Fibrillation): Predictors, Characteristics, and Clinical Outcomes. J Am Coll Cardiol. 2014;63(20):2141-7.

13. Giugliano RP, Ruff CT, Braunwald E, Murphy SA, Wiviott SD, Halperin $\mathrm{JL}$, et al. Edoxaban versus warfarin in patients with atrial fibrillation. N Engl J Med. 2013;369(22):2093-104.

14. Majeed A, Hwang HG, Connolly SJ, Eikelboom JW, Ezekowitz $M D$, Wallentin $L$, et al. Management and outcomes of major bleeding during treatment with dabigatran or warfarin. Circulation. 2013;128(21):2325-32.

15. Cowell RP. Direct oral anticoagulants: integration into clinical practice. Postgrad Med J. 2014;90(1067):529-39.

16. Schiele F, van Ryn J, Canada K, Newsome C, Sepulveda E, Park J, et al. A specific antidote for dabigatran: functional and structural characterization. Blood. 2013;121(18):3554-62.

17. Greinacher A, Thiele T, Selleng K. Reversal of anticoagulants: an overview of current developments. Thromb Haemost. 2015;113(5):931-42.

18. Karmacharya P, Pathak R, Ghimire S, Shrestha P, Ghimire S, Poudel DR, et al. Upper Airway Haematoma Secondary to Warfarin Therapy: A Systematic Review of Reported Cases. N Am J Med Sci. 2015;7(11):494-502. 